\title{
DISCONNECT-CONNECT-OVER-CONNECT NOMOPHOBIA
}

\author{
${ }^{1}$ MRUDULA CHANDRUPATLA \& NAVEEN KUMAR ${ }^{2}$ \\ ${ }^{1}$ Professor and Head, Department of Anatomy, Apollo Institute of Medical Sciences and Research, Hyderabad, India \\ ${ }^{2} \mathrm{MBBS}$, Apollo Institute of Medical Sciences and Research, Hyderabad, India
}

\begin{abstract}
Nomophobia is the condition seen in the modern era, where people fear of being unable to connect through a mobile phone. The use of smart phone has increased immensely in this present world.But, the effect of these mobile phones on the people well-being and the problem they face when they are withdrawn is to be understood. This study is done to know effects of mobile phone use and prevalence of nomophobia. Method: A Questionnaire regarding mobile phone use was administered to students studying in Apollo medical college, Hyderabad and the results were tabulated and analysed. Results: According to the study, it was found that there is increasing prevalence of Nomophobia among students. It was found that students had lack of sleep because of excessive use of mobile phone, and which indirectly created stress and strain. Conclusions: Prevention is better than cure. The study was conducted with students, who were in young age group and the future pillars of our country. Proper education regarding the use of mobile phone, and the ill effects caused by its improper use are being discussed.

KEYWORDS: Nomophobia, Anxiety, Stress
\end{abstract}

Received: Feb 21, 2020; Accepted: Mar 11, 2020; Published: May 19, 2020; Paper Id.: IJMPSDJUN20203

\section{INTRODUCTION}

Technology has advanced to a great extent that the modern technology is all about speed and efficiency. The old technology has modified and advanced to a complete extent to the present modern technology. This modern gadgets and other devices resulted in a lot of impact which is not measurable. This impact varies from good to bad depending on the technology. "Nomophobia" [3] is the psychological condition in modern world where there is fear of being unable to communicate through a mobile phone (MP) or the Internet. This word "nomophobia" has originated in England and is derived from the expression "No Mobile Phobia", that is, the phobia of being without a mobile phone. Nomophobia [4] also refers to a condition where collection of behaviours or symptoms related to MP use. This can also cause the individual people preoccupied with the mobile phone, and in turn, can result in anxiety and depression if not used regularly.

\section{OBJECTIVES}

The study is conducted to know the prevalence and dependence of mobile phone use among the students. It also helps to know the hazards with its over usage.

\section{MATERIAL AND METHODS}

The study is done in Apollo medical college, Hyderabad and it is a cross sectional study. Ethics approval was obtained from Institutional ethics committee of the college. The participants included are the students from year 1 to year 5 from 2014 to 2019. Before the study is conducted informed consent is taken from students who are involved in the study.A standard questionnaire is prepared and is validated after a pilot test. The questionnaire is been 
administered to the students of MBBS(500) of all phases and the results arestatistically analysed.

\section{RESULTS}

The feedback of the students' results were obtained from 500 students and analysed.

Table 1

\begin{tabular}{|c|c|c|c|}
\hline \multicolumn{2}{|r|}{ Questionnaire on Use of Mobile Phone } & Yes & No \\
\hline 1. & Mobile phone is used routinely all day & $76 \%$ & $24 \%$ \\
\hline 2. & Will you leave home or come out without taking your phone & $36 \%$ & $64 \%$ \\
\hline 3. & Will you come back and take if you forget the mobile phone & $60 \%$ & $40 \%$ \\
\hline 4. & When you forget phone do you feel anxious & $78 \%$ & $22 \%$ \\
\hline 5. & Per day do you make OR receive more than three calls & $68 \%$ & $32 \%$ \\
\hline 6. & When you are in restaurant or in company of other people will you turn off mobile phone & $2 \%$ & $98 \%$ \\
\hline 7. & Will you keep your MP throughout the day even in sleep & $82 \%$ & $18 \%$ \\
\hline 8. & When mobile phone has no signals, battery charge, or is out of range will you feel stressed & $80 \%$ & $20 \%$ \\
\hline 9. & Will you feel dependent on your MP & $72 \%$ & $28 \%$ \\
\hline 10. & Will you feel insecure without your MP & $48 \%$ & $52 \%$ \\
\hline
\end{tabular}

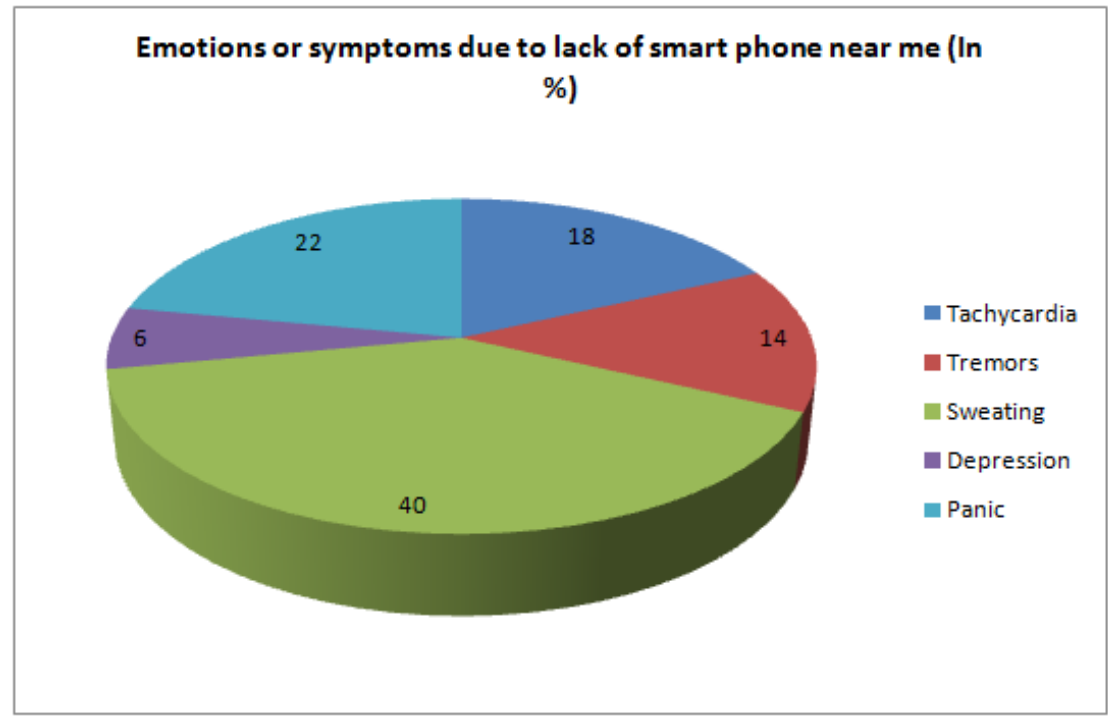

Figure 1

Biggest concern when we lose mobile phone is:
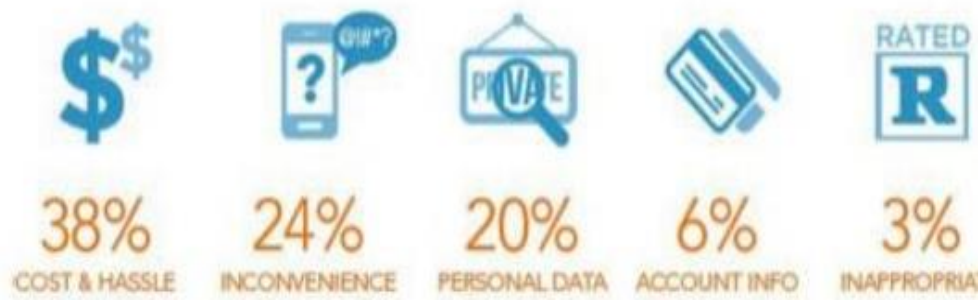

Figure 2

\section{DISCUSSIONS}

Mobile phone usage is so common in the present day, and its use has become routine and a regular habit. People became so addictive to its use and "possibly the biggest non-drug addiction of the 21 st century". Nomophobia is a clinical and psychological condition, where there is fear of being without a mobile phone and in no contact with the phone. It is the 
condition called also as telephone fear. It is not the condition where people have fear of losing, forgetting or breaking the phone, but the condition where it is being outside of mobile phone contact. A number of social phobias are there, among which nomophobia is also included.

According to the study conducted by Sharma N et al (2015) ${ }^{4}$ in Indore, among Indian medical students, it was seen that the prevalence of nomophobia was 73\%, in Bangalore study done by Masthi NR et al (2012) $)^{5}$ the prevalence of nomophobia was identified as $67 \%$. And, thestudy done by Bivin JB et al (2013) ${ }^{6}$ reported that $91.04 \%$ of the study subjects were using mobile phones for more than 3 years. In the present study, it was shown that the prevalence is more than $76 \%$.

A study done by Dixit et al (2009) ${ }^{7}$ shows that $73 \%$ of students keep the phone with them throughout the day. Study conducted in Mumbai by Market Analysis and Consumer Research Organisation (MACRO) found that 58\% of the people cannot manage and stay without having the phone even for $24 \mathrm{hrs}$ and in the present study, it shows $83 \%$.

A study conducted by Nikhita CR et al $(2015)^{8}$ found out that dependence of mobile phone increased with more use for number of years. Dongre et al. reported that increased mobile phone usage causes lack of sleep and eyestrain ${ }^{9}$ with increased use.

In the modern world, addiction to mobile phone has been an emerging problem. This is because of over and excessive use and reduction in face to face contact.

American Psychiatric Association considers that internet gaming/social media use is categorized as a non-substance related addictive disorder and considered as mental illness ${ }^{10}$.

The dependence and use of mobile phone is not a problem, but can be considered as a symptom. Use of smart phones is more common due to the availability of fast internet connectivity, which is been provided by various services a low cost. The condition of Nomophobia can be identified and modified at the early stage. Efforts should be made from home only, where parents can motivate the children about the outdoor games and channelize them in a creative way.

\section{CONCLUSIONS}

Nomophobia is an emerging problem of the modern era, which may lead to social, mental and physical health hazards. Appropriate steps are to be taken to tackle the growing problem for the welfare of the society.

\section{REFERENCES}

1. Mittal A, Rajasekar VD, Krishnagopal L, A Study to Assess Economic Burden and Practice of Cell Phone Disposal among Medical Students. Journal of Clinical and Diagnostic Research 2013; 7(4): 657-660.

2. King AL, Valenca AM, Silva AC, Sancassiani F, Machado S, Nardi AE. Nomophobia. Impact of Cell Phone Use Interfering with Symptoms and Emotions of Individuals with Panic Disorder Compared with a Control Group. Clinical Practice \& Epidemiology in Mental Health 2014;10:28-35.

3. Cheever NA, Rosen LD, Carrier LM, Chavez A. Out of sight is not out of mind: The impact of restricting wireless mobile device use on anxiety levels among low, moderate and high users. ELSEVIER. Computers in Human Behaviour 2014;37:290-297.

4. Ali, Abid, WasfiDhahir, and SamaherSabri Hameed. "A Study on Factors Inducing Stress Among Students in Nursing College." International Journal of Human Resources Management (IJHRM) ISSN (P) (2018): 2319-4936.

5. Sharma N, Sharma P, Wavare RR. Rising concern of nomophobiaamong Indian medical students. Int J Res Med Sci2015; 3(3):705-707. 
6. Masthi NR, Yashasvini. Mobile Phone dependence amongCollege Students in Bangalore. RGUHS J Med Sciences 2012April; 2(2): 84-87.

7. AAlnajjar, Ahmed. "Worrying About What? An Investigation of the Phenomenon of Worry Among Students of the United Arab Emirates University." International Journal of Humanities and Social Sciences (IJHSS) 6.6 (2017): 1-14.

8. Bivin.JB, Mathew P, Thulasi PC, Philip J. Nomophobia - dowe really need to worry about? Reviews of progress 2013May; 1(1):1-5.

9. Dixit S, Shukla H, BharwatAK, Bindal A, Goyal A, Zaidi A et al.A study to evaluate mobile phone dependence among students of a medical college and associated hospital of central India. Indian J Community Med.2010; 35; 339-41

10. Indahwati, Nanik, and KolektusRistanto. "The application of pettlep imagery exercise to competitive anxiety and concentration in Surabaya archery athletes." International Journal of Educational Science and Research (IJESR) 6.3 (2016).

11. .Nikhita CR, Jadhav PR, Ajinkya SA. Prevalence of mobilephone dependence in secondary school adolescents. Journalof Clinical and Diagnostic Research. 2015 Nov; 9(11):6-9.

12. Tabassum, R. A. B. I. A., and N. A. E. E. M. Mohsin. "Depression and anxiety among parents of children with disabilities: a case study from developing world." International Journal of Environment, Ecology, Family and Urban Studies 3.5 (2013): 33-40.

13. Dongre AS, Inamdar IF, Gattani PL. Nomophobia: A study to evaluate mobile phone dependence and impact of cell phone on health. Natl J Community Med 2017; 8:688-93.

14. Substance-Related and Addictive Disorders. In: Diagnostic and Statistical Manual of Mental Disorders-5; 2013 